\title{
Targeted gene delivery in tumor xenografts by the combination of ultrasound-targeted microbubble destruction and polyethylenimine to inhibit survivin gene expression and induce apoptosis
}

Zhi-Yi Chen ${ }^{1 *}$, Kun Liang ${ }^{2}$, Ri-Xiang Qiu ${ }^{3}$

\begin{abstract}
Background: Noninvasive and tissue-specific technologies of gene transfection would be valuable in clinical gene therapy. This present study was designed to determine whether it could enhance gene transfection in vivo by the combination of ultrasound-targeted microbubble destruction (UTMD) with polyethylenimine (PEI) in tumor xenografts, and illuminate the effects of gene silencing and apoptosis induction with short hairpin RNA (shRNA) interference therapy targeting human survivin by this novel technique.

Methods: Two different expression vectors ( $p C M V-L U C$ and pSIREN) were incubated with PEI to prepare cationic complexes (PEI/DNA) and confirmed by the gel retardation assay. Human cervical carcinoma (Hela) tumors were planted subcutaneously in both flanks of nude mice. Tumor-bearing mice were administered by tail vein with PBS, plasmid, plasmid and SonoVue microbubble, PEI/DNA and SonoVue microbubble. One tumor was exposed to ultrasound irradiation, while the other served as control. The feasibility of targeted delivery and tissue specificity facilitated by UTMD and PEI were investigated. Moreover, immunohistochemistry analyses about gene silencing and apoptosis induction were detected.

Results: Electrophoresis experiment revealed that PEI could condense DNA efficiently. The application of UTMD significantly increases the tissue transfection. Both expression vectors showed that gene expressions were present in all sections of tumors that received ultrasound exposure but not in control tumors. More importantly, the increases in transgene expression were related to UTMD with the presence of PEI significantly. Silencing of the survivin gene could induce apoptosis effectively by downregulating survivin and bcl-2 expression, also cause upregulation of bax and caspase-3 expression.

Conclusions: This noninvasive, novel combination of UTMD with PEI could enhance targeted gene delivery and gene expression in tumor xenografts at intravenous administration effectively without causing any apparently adverse effect, and might be a promising candidate for gene therapy. Silencing of survivin gene expression with shRNA could be facilitated by this non-viral technique, and lead to significant cell apoptosis.
\end{abstract}

\footnotetext{
* Correspondence: winchen1408@126.com

'Department of Medical Ultrasound, The Third Affiliated Hospital of

Guangzhou Medical University, Guangzhou 510150, PR China

Full list of author information is available at the end of the article
} 


\section{Introduction}

Gene therapy holds great promise for the treatment of cancer diseases. Successful gene therapy requires safe and efficient delivery systems [1]. Most viral vectors pose a potential risk of insertional mutagenesis and interference responses [2]. Nonviral delivery systems are safe and easy to apply, but suffer from low transfection efficiency and transient gene expression [3]. Although methods such as cationic polymers could enhance the gene transfection in vitro [1], the results of in vivo studies were still not so satisfactory because targeting vectors have to overcome chemical and structural barriers to reach cells [4]. Therefore, non-viral gene transfer has low efficiency in vivo and transfection with intravenously administered plasmid DNA is difficult [5]. More recently, in order to elevate the transfection efficiency of non-viral vector system, microbubble and the sonoporation inducted by ultrasound could be used to increase the uptake of plasmid DNA targetedly [6-9]. Ultrasound-targeted microbubble destruction (UTMD), as a means of stimulating cell membrane permeabilisation for the purposes of transferring plasmid DNA or drug into cells, has offered advantage over viral technologies [10-12]. When UTMD was combined with cationic polymers or liposome, the gene transfection efficiency had been markedly improved [4,11,13-16]. However, most studies with this technology have mainly used reporter gene to show transfection rather than efficacy in cancer gene therapy.

Survivin, the smallest member of the mammalian inhibitors of the apoptosis protein (IAP) family $[17,18]$, is upregulated in various malignancies to protect cells from apoptosis $[18,19]$, which justifies its role as a rational target for cancer therapy [20]. RNA interference (RNAi) is a potent and convenient technique, and is widely used in the applications such as gene function analysis [7,21,22]. RNAi mediated survivin knock-down in different cell lines caused increased apoptosis rates and cell cycle arrest, reduced viability and clonogenic survival as well as chemosensitization and radiosensitization $[20,23,24]$. In contrast to chemically synthesized, sequence-specific double-stranded short interference RNA (siRNA), short-hairpin RNA (shRNA) expression vectors could be used to establish stable gene expression, and could be a powerful tool for anticancer therapy $[21,22]$. Apoptosis induction by shRNA targeting survivin represents an efficient, novel strategy for cancer gene therapy [25-27]. These shRNA expression vectors could be deliveried by UTMD systems, but related study was rare [28].

For this purpose, in this present study, gene transfer of tumor xenografts in nude mice was performed through intravenous injection using the method of the combination of UTMD and polyethylenimine (PEI). We also tested the effects of gene silencing and apoptosis induction with shRNA interference therapy targeting human survivin by this novel technique. The result showed that, transfection efficiency was significantly improved and provided a new way for in vivo cancer gene therapy.

\section{Materials and methods \\ Preparation of Plasmid DNA}

pCMV-LUC (7.4 kb) was constructed by cloning the luciferase gene from the pGL3-Promoter Vector (5.01 kb, Promega Corp., Madison, WI, USA) into pcDNA3.1 (5.42 kb, Invitrogen, San Diego, CA, USA) at the Bam $\mathrm{HI}$ and Hind III sites [29].

The pSIREN-DNR-DsRed-Express Vector $(6,7 \mathrm{~kb}, \mathrm{BD}$ Biosciences Clontech, USA), was an expression vector for red fluorescence protein (RFP) gene, which excitation and emission maxima occur at $557 \mathrm{~nm}$ and 579 $\mathrm{nm}$, respectively. A shRNA expression vector targeting human survivin gene (GenBank accession no. NM_001168) was designed and synthesized as described previously [28]. The selected reconstructed plasmid for transfection was extracted and purified using a Qiaquick Kit (Qiagen, Crawley, UK). The double strand oligos generating survivin shRNA were subcloned into linearized expression vector at the Bam $\mathrm{HI}$ and EcoR I sites. The specific recombinant shRNA vector was named pSIREN-S. Similarly, a non-specific control vector was constructed, which was named pSIREN-C.

The concentration of isolated plasmid DNA was determined by absorbance at $260 \mathrm{~nm}$ wavelength (A260) using UV spectrophotometry (DU-640, Beckman Coulter, Fullerton, CA, USA) and resuspended to a final concentration of $1 \mu \mathrm{g} / \mu \mathrm{l}$ in buffer. In addition, the absorbance ratio of the A 260 to A 280 was between 1.8 and 2.0, indicating that the purified plasmid DNA was free of contaminants. The recombinant plasmid was evaluated by Bio Imaging Systems (Syngene, Synoptics Ltd, Cambridge, UK).

\section{Preparation of Transfection Complexes}

Branched PEI with an average molecular weight of 25 $\mathrm{kDa}$ was obtained from Sigma-Aldrich (St. Louis, MO, USA). An aqueous stock solution of PEI was prepared by diluting $1 \mathrm{mg}$ of the commercial solution in $1000 \mathrm{ml}$ DI water, neutralized with $\mathrm{HCl}$ and filtering at $0.2 \mu \mathrm{m}$ (Millipore, Bedford, MA, USA). Two PEI/DNA complexes were performed by mixing PEI and plasmids at 1:4 to $8: 1$ of N/P ratio [PEI nitrogen: DNA phosphate ratio, based on the recognition that $1 \mu$ l of PEI stock solution contains $10 \mathrm{nmol}$ of amine nitrogen and $1 \mu \mathrm{g}$ of DNA contains $3 \mathrm{nmol}$ of phosphate [30]]. 
The complexes incubated for 20-30 min at room temperature and stored in $4^{\circ} \mathrm{C}$. Electrophoresis was carried out for $40 \mathrm{~min}$ at $80 \mathrm{~V}$. The separations were visualized to determine the optimal ratio of PEI/DNA complexes.

The suspension of SonoVue microbubbles (Bracco Research, Switzerland) were reconstituted before use by injecting $5 \mathrm{~mL}$ of $0.9 \%$ saline solution. Before the experiments, plasmid DNA (30 $\mu \mathrm{g})$ or PEI/DNA complexes and SonoVue microbubble $(100 \mu \mathrm{L})$ were gently agitated with phosphate buffered saline (PBS) to a final volume of $200 \mu \mathrm{L}$ to prepare the transfection complexes (P/ SonoVue and $\mathrm{P} /$ SonoVue/PEI, $\mathrm{P}$ indicated as plasmid) as detailed previously [11]. All the complexes were prepared by incubation for $15 \mathrm{~min}$ at room temperature.

\section{Cell Culture}

Human cervical cancer cell lines (HeLa) were obtained from China Center for Type Culture Collection (CCTCC) and incubated in Dulbecco's modified Eagle's medium (DMEM, Gibco, USA) with 10\% fetal bovine serum (FBS, Gibco, USA) and $100 \mathrm{U} / \mathrm{ml}$ penicillin, 100 $\mu \mathrm{g} / \mathrm{ml}$ streptomycin, at $37^{\circ} \mathrm{C}$ in a humidified environment of $5 \% \mathrm{CO}_{2}$ and $95 \%$ air. Total cell count was determined with a hemocytometer (Burker Turk). Initial cell viability was determined by means of exclusion with trypan blue dye (Sigma-Aldrich, USA). Exponentially growing cells were used in all experiments. Before animal modeling, Hela cells were harvested, collected and centrifuged, and then resuspended in $100 \mu \mathrm{L}$ DMEM to prepare single cell suspension.

\section{Animal Protocol}

Female Balb/c (nu/nu) mice, 4-6 week old, weighing 15-21 g, were purchased from experimental animal research center. All the mice were treated and housed according to approved guidelines (Guidelines for the Care and Use of Laboratory Animals).

The mice were fixed on superclean bench according to the principle of aseptic operation, and inoculated subcutaneously into the flank with $2 \times 10^{6}$ cells per mouse after local sterilized. The mice were continued to be raised at specified pathogen free (SPF) qualification after operation, being observed one time every two days. Two weeks later, the experiments were initiated when the tumors reached a size of 5-10 mm.

\section{Experimental Grouping of Gene Delivery}

To analyze the impact of the combination of UTMD and PEI on the RFP expression, nude mice bearing tumor xenografts were selected, randomly divided into four groups, four mice each group: A group: PBS group (negative control); B group: naked pSIREN-C group; C group: pSIREN-C/SonoVue group; D group: pSIREN-C/ SonoVue/PEI group.
To investigate the effect of UTMD combined with PEI on the luciferase activity, another 20 nude mice were selected, randomly divided into five groups, four mice each group, a group; PBS group (negative control); b group: naked pCMV-LUC group; c group: pCMVLUC/SonoVue group; d group: pCMV-LUC/SonoVue/ PEI group; e group: after the injection of pCMV-LUC/ SonoVue/PEI complexes, the tumor xenografts were not received ultrasound irradiation and compared with group $d$ to understand the impacts of this transfection method and ultrasound irradiation on other non-target organs (livers, kidneys, lungs, hearts). In other groups, only one side of the tumor xenografts was received irradiation, while the other served as control.

The total dose of injection was $200 \mu \mathrm{l}$, and the plasmid dosage was $30 \mu \mathrm{g} /$ mouse. The microbubbles were mixed with plasmid solution or PEI/DNA complex at the proportion of 1:1. All the plasmid DNA or complexes were administrated by tail vein. The mice were anesthetized by diethylether and fixed on the flats. The tumor xenografts were subsequently sonicated by a transducer (Accusonic, Metron Medical Australia Pty. Ltd.) placed on the skin with contact gel (Aquasonic 100, Parker Laboratories Inc., USA). Ultrasound parameters were set at $3 \mathrm{MHz}, 2 \mathrm{~W} / \mathrm{cm}^{2}, 2 \mathrm{~min}$, duty cycle $20 \%$. During the exposure, the ultrasound transducer was moved around in a circular motion to ensure the whole tumor xenograft exposed.

\section{Analysis of Transfection Efficiency}

3 days after ultrasound treatment [9], nude mice were sacrificed by cervical dislocation. The specimens of tumor xenografts, the skins around the tumors, hearts, livers and lungs, were immediately harvested, embedded in optimal cutting temperature compound (OCT, Tissue-Tek, Sakura Finetek, Torrance, CA, USA), and stored at $-80^{\circ} \mathrm{C}$ until further analyses. Cross sections $(10$ $\mu$ m-thick slices) were cut with a cryostat (CM1900, Leica, Germany) and affixed to glass slides. Fluorescence expression and distribution pattern were observed with confocal laser microscopy (Fluoview FV500, Olympus, Japan). Digital image subtraction method was devised to eliminate autofluorescence. Slices were coded so that analyses were performed without knowledge of which treatment each individual animal had received. For each sample, RFP expression and transfection efficiency were evaluated in six randomly chosen fields per section.

For examination of luciferase reporter gene expression, tumor xenografts and the non-targeted organs in group $\mathrm{d}$ and e were removed and homogenized, frozen in liquid nitrogen, and stored at $-80^{\circ} \mathrm{C}$. Luciferase activity in the tissue lysate was measured using a Lumat LB9507 instrument (Berthold, Bad Wildbad, Germany). Luciferase background (100-200 RLU) was subtracted 
from each value and transfection efficacy is expressed as RLU/organ or RLU/tumor [31]. One million RLU correspond approximately to $2 \mathrm{ng}$ luciferase.

\section{Gene Silencing and Apoptosis Induction Effects of shRNA Expression Vector Targeting Survivin Transfected by UTMD and PEI}

A total of 18 mice were randomly divided into 3 experimental groups, 6 mice each group. Control group, mice were received injections of PBS; pSIREN-S +UTMD group, mice were received injections of pSIREN-S/SonoVue and followed by local ultrasound irradiation; pSIREN-S + UTMD + PEI group, mice were received injections of pSIREN-S/SonoVue/PEI complexes and followed by local ultrasound irradiation. All injections were performed with the plasmid DNA dose of $30 \mu \mathrm{g} /$ mouse. The number of dead mice was noted every day. 21 days after injection, the tumor-bearing mice were humanely sacrificed and the solid tumors were harvested.

\section{Immunohistochemistry}

The samples were fixed with formaldehyde, dehydrated with a graded alcohol series, and embedded in paraffin. The sections were incubated with primary antibodies against survivin, bcl-2, bax and caspase-3 (1:100 dilution, Santa Cruz Biotechnology) and then incubated with appropriate biotinylated secondary antibody as detailed previously [32]. The colorimetric detection was performed by using a DAB detection kit (Boster Biological Technology Co. Ltd., Wuhan, China). Images were acquired with a microscope (BX51, Olympus, Japan). The assessment of the immunohistochemical results were modified from that described previously [33,34]. The percentage of cells expressing the marker were classified qualitatively based on the intensity of staining and the percent of cells as follows: score 1: no reactivity; score 2: low intensity staining in less than $10 \%$ of cells; score 3: low to moderate intensity staining in $11 \%$ to $30 \%$; score 4 : moderate to strong staining in $31 \%$ to $50 \%$; score 5 : diffuse, strong intensity staining in $50 \%$.

\section{Histopathology}

Serial sections of tumor tissue were processed for routine histological examination. The specimens were washed with PBS to remove blood, fixed with formaldehyde, dehydrated with a graded alcohol series, and embedded in paraffin. Hematoxylin eosin staining (H\&E) was performed on the specimens, for histopathologic evaluation of hemorrhage, necrosis, and inflammation.

\section{Statistical Analysis}

Statistical analyses were performed by the SPSS 13.0 software package (SPSS, Inc, Chicago, IL). All values were expressed as mean \pm SD. Analysis of variance with $t$ test and analysis of variance (ANOVA) test were used to determine the significance of the difference in a multiple comparison. If the ANOVA was significant, the Tukey's procedure was used as a post hoc test. Differences with a $P$ value of less than 0.05 were considered to be statistically significant.

\section{Results}

\section{Identification of pCMV-LUC by Restriction Enzymes} Digestion

After double-enzyme cutting by Bam HI and Hind III, the restriction enzymes digestion results showed that the objective fragment of the pCMV-LUC plasmid could be detected at around $2000 \mathrm{bp}$, which was exactly coincidence with the size of the designed DNA (Figure 1).

\section{Gel Retardation Analysis of PEI/DNA Complexes}

Agarose gel electrophoresis analysis showed that (Figure 2 ), with the increase of $\mathrm{N} / \mathrm{P}$ ratio of PEI/DNA complexes, the plasmid DNA migrated more slowly. When $\mathrm{N} / \mathrm{P} \geq 3$, the plasmid DNA migration could not be

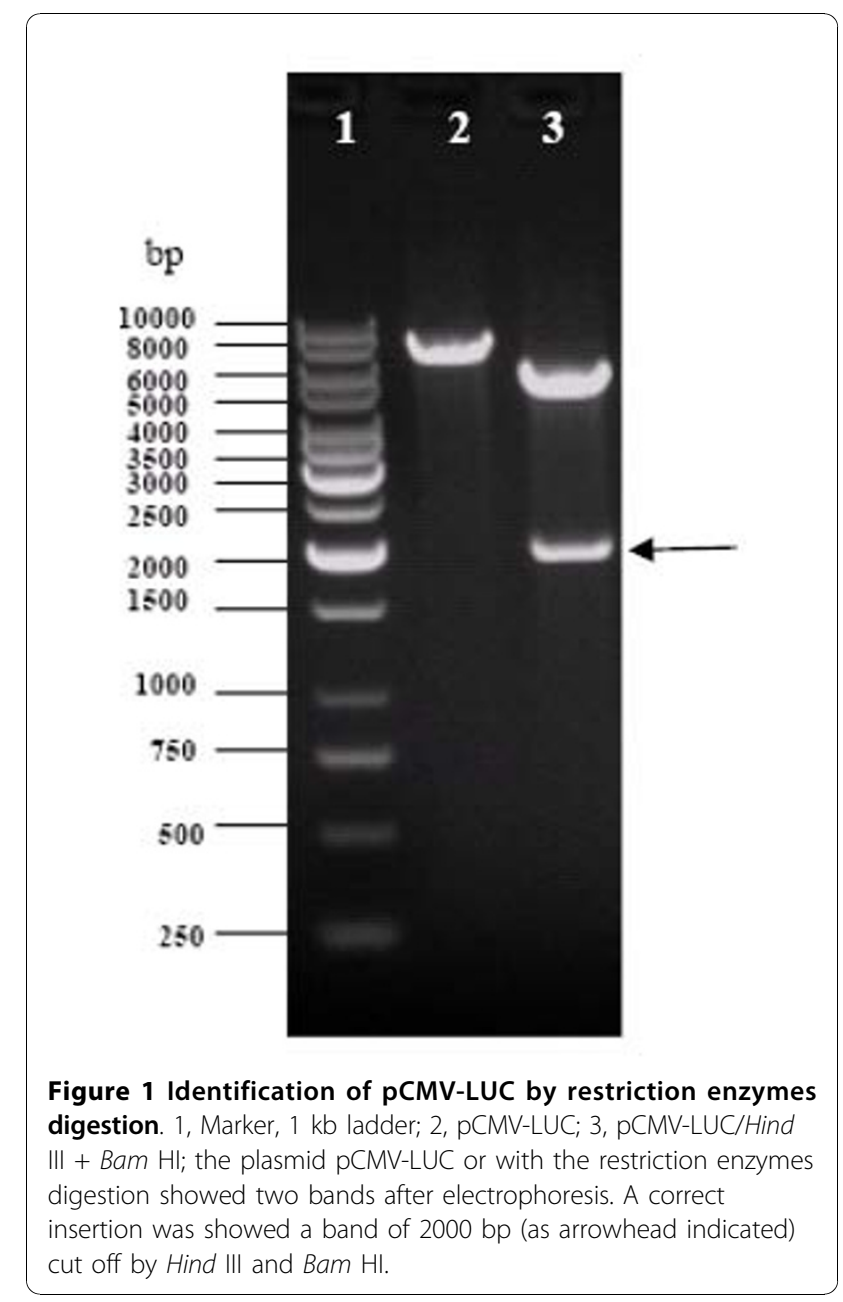



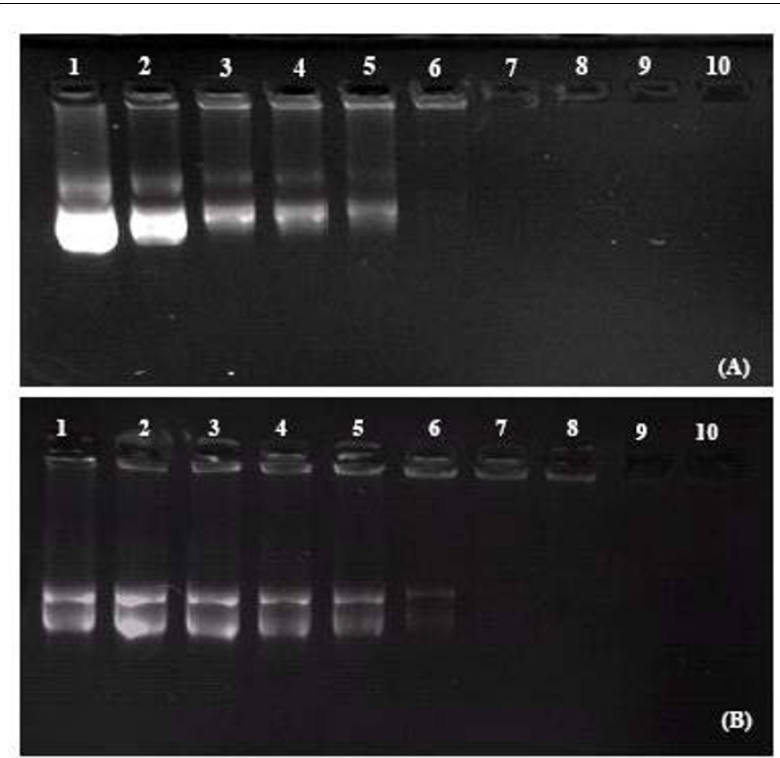

Figure 2 Electrophoretic patterns of plasmid DNA complexes prepared with $\mathrm{PEI}$ at various N/P ratios: N/P ratio $=\mathrm{PEI}$ nitrogen/DNA phosphate; (A) pCMV-LUC, (B) pSIREN-S. Lanes 1-10: the N/P molar ratios of $1 / 4,1 / 2,1,3 / 2,2,5 / 2,3,4,6$, and 8 .

observed, and the PEI/DNA complexes with positive charge remained in the hole. PEI could effectively condensate the plasmid DNA, and the electrophoresis analyses of both plasmids were similar (Figure 2A-B). According to the results of electrophoresis, the N/P ratio was chose for 6 in this study and used in the following experiments.

\section{Enhanced RFP Expression in Transplanted Tumors by Combination of UTMD and PEI}

Regardless of ultrasound irradiation, there was no obvious RFP expression in Group A and B (Figure 3A-B). Without ultrasound irradiation, there were only a few cells expressing RFP in pSIREN-C/SonoVue group and red fluorescent signal was weak in the majority of samples (Figure $3 \mathrm{C}$ ). However, the RFP expression was enhanced and increased when the injection of plasmid DNA and SonoVue combined with ultrasound irradiation (Figure 3D), but it was still weaker than that of pSIRENC/SonoVue/PEI group (Figure 3E). When UTMD combined with PEI, RFP expression was increased significantly with strong density and signal (Figure 3F).

\section{Enhanced Luciferase Activity by Combination of UTMD and PEI}

The luciferase expression could not be increased by ultrasound irradiation after the injection of naked plasmid $(t=-2.174, P=0.095$, Figure 4$)$. Without ultrasound exposure, microbubble could not significantly improve the luciferase activity of tumor tissues. But the

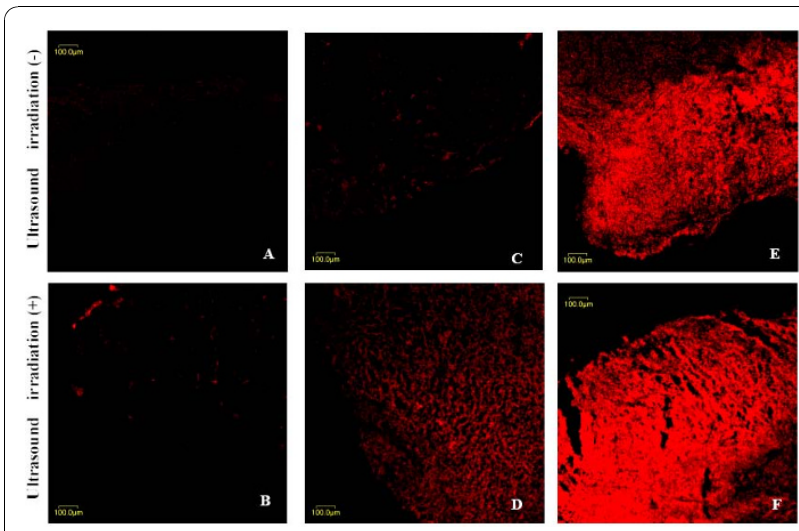

Figure 3 Fluorescent microphotographs of the tumor xenografts in nude mice after intravenous injection of naked pSIREN-C (A, B), pSIREN-C/SonoVue complex (C, D) and pSIREN$\mathrm{C} /$ SonoVue/PEI complex (E, F) with or without ultrasound irradiation. Ultrasound irradiation parameters were as follow, irradiation time $=2 \mathrm{~min}$, intensity $=2 \mathrm{~W} / \mathrm{cm}^{2}$, frequency $=3 \mathrm{MHz}$, and duty cycle $=20 \%$. UTMD $=$ ultrasound targeted microbubble destruction; $\mathrm{PEI}=$ polyethylenimine; $\mathrm{bar}=100 \mu \mathrm{m}$.

application of UTMD could significantly promote the transfection efficiency $(t=-11.433, P<0.01)$, with the luciferase expression increased by about 14 fold.

The transfection efficiency was the highest when UTMD combined with PEI. As compared with nonirradiated tumor, the luciferase activity of irradiated samples has increased by about 10 fold $(t=-11.633, P<0.01)$. And the luciferase expression increased by about 111 fold when compared with that of non-combined PEI group $(P<0.01)$. This demonstrated that the combination of UTMD with PEI would significantly facilitate the transfection efficiency.

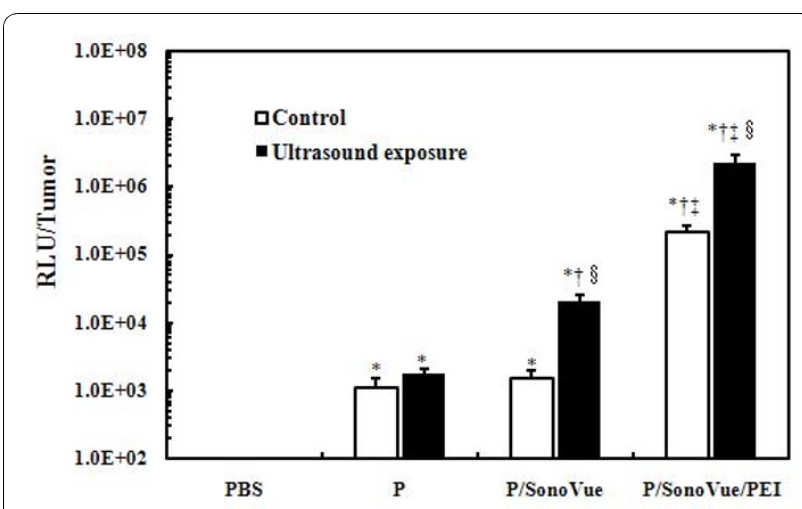

Figure 4 Luciferase expressions of tumor xenografts in nude mice with UTMD and PEI. Control: non ultrasound exposure; P: PCMV-LUC; in the same condition (control or ultrasound exposure), as compared with PBS group, ${ }^{*} P<0.01$; as compared with $\mathrm{P}$ group, $\dagger P<0.01$; as compared with $P /$ SonoVue group, ${ }^{\ddagger} P<0.01$; as compared with control group, ${ }^{\S} P<0.01$. 


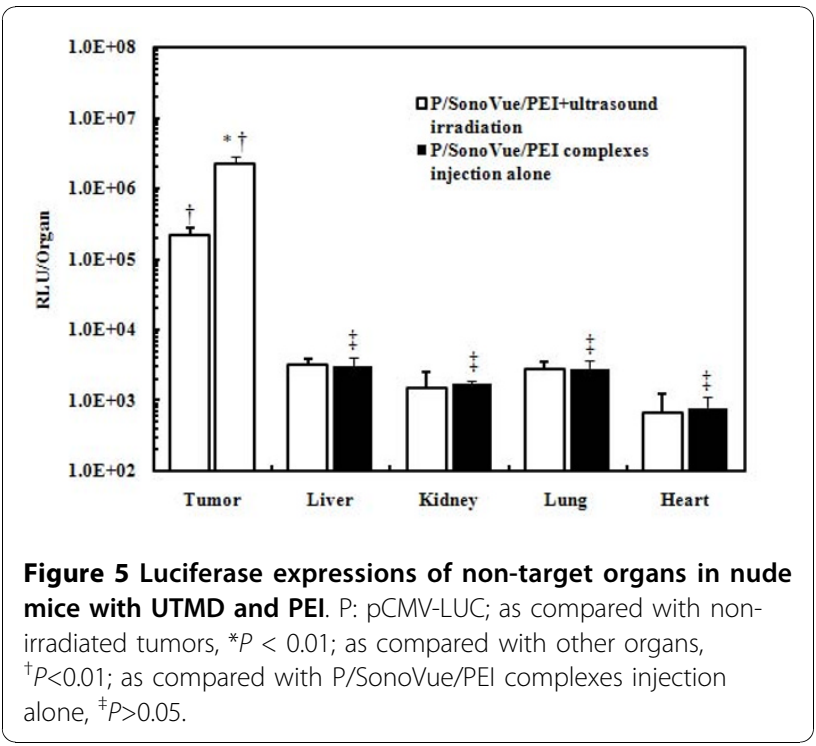

\section{Analysis of Tissue Targeting}

As shown in Figure 5, when the tumor xenografts was irradiated (group d), the increase extent of luciferase activity was significantly higher than that of non-irradiated tumor and other tissues and organs (all $P<0.01$ ). Livers, lungs, kidneys and hearts in group $\mathrm{d}$, e, had relative low luciferase activity level, but all were lower than that of the tumor xenografts $(P<0.01)$. The ultrasound irradiation of the transplanted tumors had no evident impact on other organs $(P>0.05)$.

\section{Degradation of Survivin Was the Main Trigger for Apoptosis Induction in Nude Mice}

As shown in Figure 6A(a-b) and 6B, the microscopic examination of stained tumor sections showed that the score of survivin expression in control group and pSIREN-S +UTMD group were significantly higher than that of pSIREN-S + UTMD + PEI group (both $P<0.01$ ). Comparing with that of control and pSIREN-S + UTMD group, the score of bcl-2 protein expressions in pSIREN$\mathrm{S}+\mathrm{UTMD}+\mathrm{PEI}$ group also resulted in downregulation markedly (both $P<0.01$, Figure 6A(c-d) and 6B). Moreover, As shown in Figure B, score of bax [Figure 6A(e-f)] and caspase-3 [Figure $6 \mathrm{~A}(\mathrm{~g}-\mathrm{h})$ ] protein expressions in pSIREN-S + UTMD + PEI group was upregulated remarkably as comparing with control group and pSIREN-S + UTMD group (all $P<0.01$, Figure $6 \mathrm{~B}$ ).

\section{Histology Examination}

In pSIREN-S + UTMD + PEI group, H\&E staining showed that the integrities of tumor xenografts were good. The histologic structure of livers, kidneys, lungs, hearts and other organs were normal, and no necrosis or fibrosis changes were seen. Moreover, the results

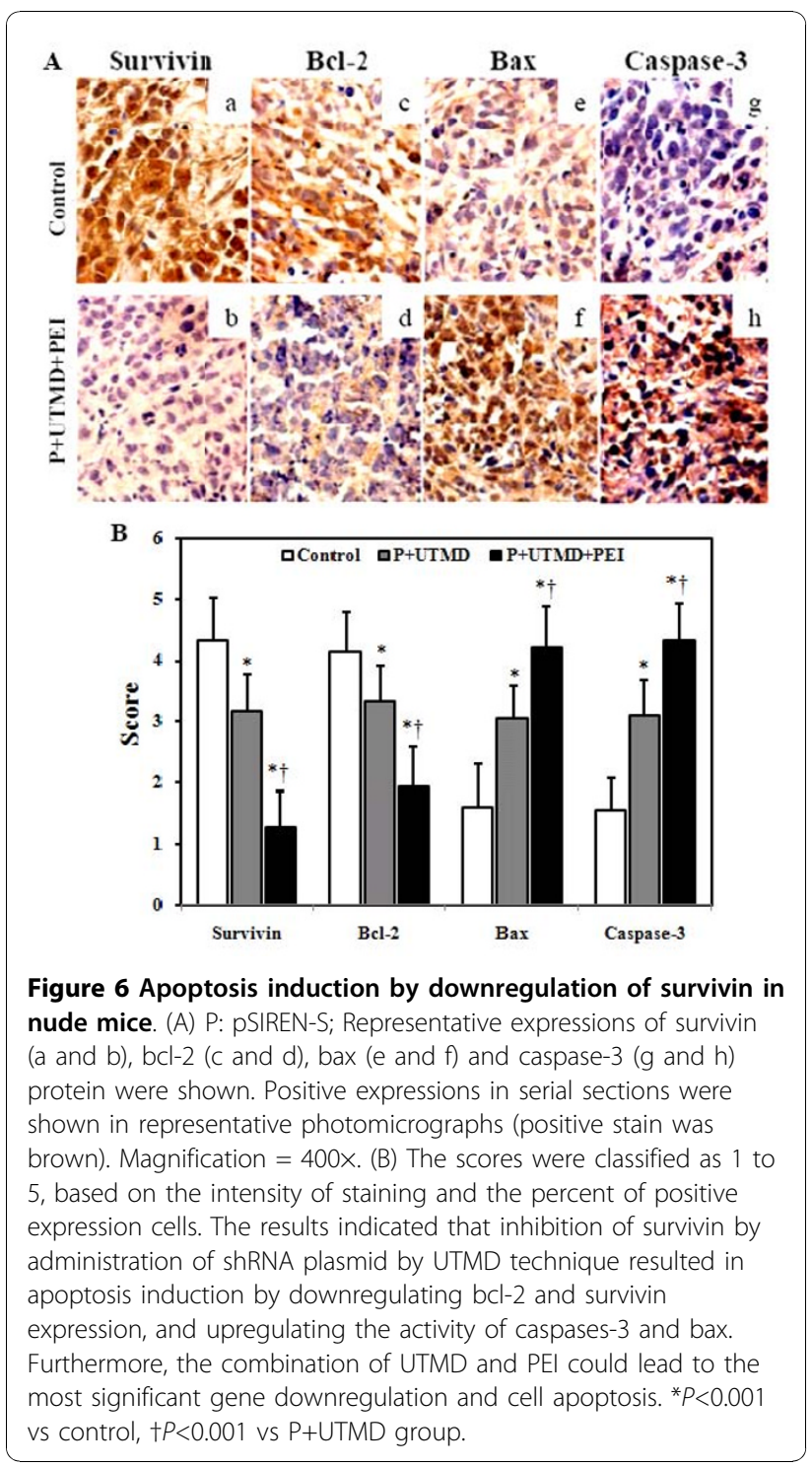

showed no abnormalities such as inflammation or degeneration in any tissues.

\section{Discussion}

PEI, as one of the most effective poly-cationic gene vectors, could condense plasmids DNA into cationic polymers, protect the plasmids against being degraded by nucleinase or enzymes within a few hours, and enhance the endocytosis of plasmids DNA, thus promoting gene transfection in vivo $[31,35]$. On the other hand, ultrasound could increase transfection efficiency in vivo and in vitro. Microbubbles could significantly improve the transgenic expression. Moreover, ultrasonic energy could be focused on the target site of gene transfer by local irradiation [11]. It was particularly important for gene transfer in deep tissues. A lot of literature $[13-16,36]$ reported that the combination of cationic 
polymers and ultrasound could improve transfection efficiency. Lawrie et al. [13] reported that UTMD enhanced approximately 300 fold increments in transgene expression after naked DNA transfection. While UTMD and polyplex yielded transgene expression levels approximately 3000 fold higher than after naked DNA alone. Anwer et al. [14] reported that UTMD resulted in a significant increase in gene transfer to the tumors by the tail vein injection and the maximum of expression was 270-fold. In this study, when the application of UTMD combined with PEI, the transfection efficiency for both plasmids in the tumor xenografts could be significantly improved, providing a new strategy for cancer gene therapy.

UTMD could facilitate targeted gene therapy, thus significantly enhance gene transfection in vivo. The results of our study showed that, after intravenous injection of plasmids DNA, there was obvious gene expression in the irradiated tumors. And the difference had statistical significance when compared with that of non-irradiated tumors. Similar to our study, Haag et al. [37] established two tumors in each animal, injected the ODN-loaded microbubbles intravenously, and then exposed only one of the tumors to ultrasound. Their results showed that, digoxigenin staining intensity was significantly stronger in treated tumors $(16-49 \%)$ that were exposed to ultrasound as compared with the untreated collateral control tumors (2-18\%). Dittmar et al. [38] applied pulsed high intensity focused ultrasound to expose one tumor while the other tumor served as a control and found that local exposure in tumors could enhance expression of green fluorescent protein (GFP). Moreover, UTMD could transduce plasmids into target tissue when systemic administration rather than direct target organ delivery by catheter-based approaches or operative injection. And this was particularly important in cardiovascular as well as gene therapy of inaccessible tumors. Howard et al. [39] reported that, systemic delivery of Ad-GFP microbubbles pretreated with complement and injected in the tail vein of nude mice resulted in high level of transgene within the tumor alone. Both fluorescence microscopy and GFP immunohistochemistry demonstrated UTMD induced specific transduction in the targeted cells only, with no uptake in hearts, lungs or liver. Chen et al. [2] incorporated plasmids into the phospholipid shell of gas-filled microbubbles, which were then infused into rats and destroyed within the pancreatic microcirculation with UTMD technology. They found that UTMD allowed relatively noninvasive delivery of genes to pancreatic islets with efficiency sufficient to modulate the function of $\beta$-cell, and a low level of luciferase activity was detected in all organs within the ultrasound beam. Activity of skeletal muscle or right kidney which lie outside the ultrasound beam was not detected in their study. This data illustrated that this technique largely could prevent the problem of hepatic uptake seen with viral vectors. Moreover, study indicated [9] that the reticuloendothelial system was not a limiting factor for the ultrasound-based gene delivery with these experimental conditions. While Huber et al. [5] found that, after intratumoral DNA injection, ultrasound induced a 10 -fold increase of $\beta$-galactosidase positive cells. In contrast, ultrasound was not found to enhance reporter gene expression after intravenous plasmid application. But they did not apply the UTMD technology.

To further enhance the transfection efficiency of UTMD, DNA can be protected by the complexation of cationic polymers and microbubbles. Because both membrane of SonoVue microbubble and plasmid DNA bear a net negative charge [40], the binding of plasmid DNA and microbubbles are likely to be weak and transient. Cationic polymers, such as PEI, have strong capacity to bind to negatively charged DNA and proteins. It was hypothesized that P/PEI complexes were adsorbed to the surface of microbubbles through electrostatic interaction, and P/SonoVue/PEI complexes were formed. The complexes could be released targetedly by ultrasound irradiation. In addition, ultrasound irradiation could enhance gene transfection of tumors as well, and reduce gene expression of other non-target organs. SonoVue microbubbles could significantly increase the transfection efficiency, but further study was still needed to validate the specific mechanisms.

Just like the study of Gao et al. [41], $3 \mathrm{MHz}$ ultrasound in our study facilitated the irradiation of superficial tumor xenografts. Ultrasonic energy was more focused, and had no significant impacts on other organs. As the N/P ratio increased, the toxicity will be grater, too [31]. The results indicated that this N/P ratio in our experiment could enhance in vivo transfection efficiency effectively. But it was still need to further analysis and different N/P ratio should be compared. In addition, the transfection efficiency is related to the cell line, microbubble components and DNA vectors. Blood supply or reaction to some certain gene was different, the effects would be different. Moreover, tumor growth was very rapid in the cells with higher division rate, and cell proliferation would dilute the effect of transfection. It would lead to elimination of exogenous plasmid DNA from transfected cells [42]. Furthermore, there are lots of differences in the optimal time points among different organs and tissues, the transfection efficiency will differ for different administration ways, too. Therefore, studies of the optimization analysis of different methods of transfection mediated by the combination of UTMD and PEI should be further investigated. 
In mammalian cells, apoptosis is modulated by inhibitors of the apoptosis protein (IAP) families. Cancer cells possess defects in apoptotic, with the consequence of increased resistance to cell death. From the human cancer gene therapy perspective, using molecular antagonists of survivin was one approach which was regarded as a predominant strategy in anticancer therapy for enhancing cancer cell death [25-27]. On the other hand, for the potential use of UTMD as a therapeutic gene delivery system, it is critically important to investigate the apoptosis induction under actual physiological conditions. Diverse molecular mechanisms have been implicated in the apoptosis induction $[43,44]$. The bcl-2 family of proteins regulates various steps in apoptosis and blocks cell death, whereas pro-apoptotic proteins such as bax promote apoptosis [33,34]. Caspase-3 is the ultimate executioner caspase that is essential for the nuclear changes associated with apoptosis [45]. Moreover, survivin is known to directly or indirectly interact with caspase- 3 and subsequently inhibit its activity. In our study, microscopic examination and scoring showed that protein expressions of bax and caspase- 3 were up-regulated in $\mathrm{P}+\mathrm{PEI}+\mathrm{UTMD}$ group as compared with those of control group or P+UTMD group, while protein expressions of survivin and bcl-2 were down-regulated markedly. The data indicated that the inhibition of survivin by administration of shRNA expression vectors with the combination of UTMD and PEI resulted in apoptosis induction in nude mice by downregulating bcl-2 expression and upregulating the activity of bax and caspases-3.

\section{Conclusions}

In summary, UTMD could synergistically promote the development and application of other gene transfer methods in vivo. It could be used as a safe and effective non-viral gene delivery system. The combination of UTMD and PEI, which could significantly enhance the gene expression of plasmid DNA in the tumor tissue, was a new method of in vivo gene transfer with a good prospect. Survivin downregulation with shRNA expression vector mediated by the UTMD and PEI technique could obviously induce apoptosis in vivo. This method will provide a noninvasive, safe, promising candidate for tumor gene delivery. More researches are needed to further the efficient, promising novel technique for cancer gene therapy.

\section{Acknowledgements}

This research is supported by grant of Medical Research Foundation of Guangdong Province [No. A2010270].

\footnotetext{
Author details

'Department of Medical Ultrasound, The Third Affiliated Hospital of Guangzhou Medical University, Guangzhou 510150, PR China. ${ }^{2}$ Department
}

of Obstetrics and Gynecology, Guangzhou Research Institute of Obstetrics and Gynecology, The Third Affiliated Hospital of Guangzhou Medical University, Guangzhou 510150, PR China. ${ }^{3}$ Department of Pharmacy, The Third Affiliated Hospital of Guangzhou Medical University, Guangzhou 510150, PR China.

\section{Authors' contributions}

CZY has carried out the study design, molecular biological work, statistical analyses and drafted the manuscript. LK has contributed in literature research and helped to draft the manuscript. QRX has contributed in animal experiment. All authors read and approved the final manuscript.

\section{Competing interests}

The authors declare that they have no competing interests.

Received: 16 October 2010 Accepted: 23 November 2010 Published: 23 November 2010

\section{References}

1. LU QL, Liang HD, Partridge T, Blomley MJ: Microbubble ultrasound improves the efficiency of gene transduction in skeletal muscle in vivo with reduced tissue damage. Gene Ther 2003, 10:396-405.

2. Chen S, Ding JH, Bekeredjian R, Yang BZ, Shohet RV, Johnston SA, Hohmeier HE, Newgard CB, Grayburn PA: Efficient gene delivery to pancreatic islets with ultrasonic microbubble destruction technology. Proc Natl Acad Sci USA 2006, 103:8469-8474.

3. Oberle V, de Jong G, Drayer Jl, Hoekstra D: Efficient transfer of chromosome-based DNA constructs into mammalian cells. Biochim Biophys Acta 2004, 1676:223-230.

4. Chumakova OV, Liopo AV, Andreev VG, Cicenaite I, Evers BM, Chakrabarty S, Pappas TC, Esenaliev RO: Composition of PLGA and PEI/DNA nanoparticles improves ultrasound-mediated gene delivery in solid tumors in vivo. Cancer Lett 2008, 261:215-225

5. Huber $P E$, Pfisterer $P:$ In vitro and in vivo transfection of plasmid DNA in the Dunning prostate tumor R3327-AT1 is enhanced by focused ultrasound. Gene Ther 2000, 7:1516-1525.

6. Li YS, Davidson E, Reid CN, McHale AP: Optimising ultrasound-mediated gene transfer (sonoporation) in vitro and prolonged expression of a transgene in vivo: Potential applications for gene therapy of cancer. Cancer Lett 2009, 273:62-69.

7. Saito M, Mazda O, Takahashi KA, Arai Y, Kishida T, Shin-Ya M, Inoue A, Tonomura H, Sakao K, Morihara T, Imanishi J, Kawata M, Kubo T: Sonoporation mediated transduction of pDNA/siRNA into joint synovium in vivo. J Orthop Res 2007, 25:1308-1316.

8. Iwanaga K, Tominaga K, Yamamoto K, Habu M, Maeda H, Akifusa S, Tsujisawa T, Okinaga T, Fukuda J, Nishihara T: Local delivery system of cytotoxic agents to tumors by focused sonoporation. Cancer Gene Ther 2007, 14:354-363.

9. Hauff P, Seemann S, Reszka R, Schultze-Mosgau M, Reinhardt M, Buzasi T, Plath T, Rosewicz S, Schirner M: Evaluation of gas-filled microparticles and sonoporation as gene delivery system: feasibility study in rodent tumor models. Radiology 2005, 236:572-578.

10. Xing W, Gang WZ, Yong Z, Yi ZY, Shan XC, Tao RH: Treatment of xenografted ovarian carcinoma using paclitaxel-loaded ultrasound microbubbles. Acad Radiol 2008, 15:1574-1579.

11. Chen Z, Xie M, Wang X, Lv Q, Ding S: Efficient gene delivery to myocardium with ultrasound targeted microbubble destruction and polyethylenimine. J Huazhong Univ Sci Technolog Med Sci 2008, 28:613-617.

12. Bekeredjian R, Kroll RD, Fein E, Tinkov S, Coester C, Winter G, Katus HA, Kulaksiz $\mathrm{H}$ : Ultrasound targeted microbubble destruction increases capillary permeability in hepatomas. Ultrasound Med Biol 2007, 33:1592-1598.

13. Lawrie A, Brisken AF, Francis SE, Cumberland DC, Crossman DC, Newman CM: Microbubble-enhanced ultrasound for vascular gene delivery. Gene Ther 2000, 7:2023-2027.

14. Anwer K, Kao G, Proctor B, Anscombe I, Florack V, Earls R, Wilson E, McCreery T, Unger E, Rolland A, Sullivan SM: Ultrasound enhancement of cationic lipid mediated gene transfer to primary tumors following systemic administration. Gene Ther 2000, 7:1833-1839.

15. Xenariou S, Griesenbach U, Liang HD, Zhu J, Farley R, Somerton L, Singh $C$, Jeffery PK, Ferrari S, Scheule RK, Cheng SH, Geddes DM, Blomley M, 
Alton EW: Use of ultrasound to enhance nonviral lung gene transfer in vivo. Gene Ther 2007, 14:768-774.

16. Lu QL, Liang HD, Partridge T, Blomley MJ: Microbubble ultrasound improves the efficiency of gene transduction in skeletal muscle in vivo with reduced tissue damage. Gene Ther 2003, 10:396-405.

17. Beltrami E, Plescia J, Wilkinson JC, Duckett CS, Altieri DC: Acute ablation of survivin uncovers p53-dependent mitotic checkpoint functions and control of mitochondrial apoptosis. J Biol Chem 2004, 279:2077-2084.

18. Ai Z, Yin L, Zhou X, Zhu Y, Zhu D, Yu Y, Feng Y: Inhibition of survivin reduces cell proliferation and induces apoptosis in human endometrial cancer. Cancer 2006, 107:746-756.

19. Li F, Ambrosini G, Chu EY, Plescia J, Tognin S, Marchisio PC, Altieri DC: Control of apoptosis and mitotic spindle checkpoint by survivin. Nature 1998, 396:580-584

20. Ning S, Fuessel S, Kotzsch M, Kraemer K, Kappler M, Schmidt U, Taubert $H$, Wirth MP, Meye A: siRNA-mediated down-regulation of survivin inhibits bladder cancer cell growth. Int J Oncol 2004, 25:1065-1071.

21. Zenke K, Kim KH: Novel fugu U6 promoter driven shRNA expression vector for efficient vector based RNAi in fish cell lines. Biochem Biophys Res Commun 2008, 371:480-483.

22. Nagao A, Zhao X, Takegami T, Nakagawa H, Matsui S, Matsunaga T, Ishigaki Y: Multiple shRNA expressions in a single plasmid vector improve RNAi against the XPA gene. Biochem Biophys Res Commun 2008, 370:301-305.

23. Song $H$, Xin $X Y$, Xiao F, Wang DT, Yue QH, Han X: Survivin gene RNA interference inhibits proliferation, induces apoptosis, and enhances radiosensitivity in HeLa cells. Eur J Obstet Gynecol Reprod Biol 2008, 136:83-89.

24. Rödel F, Hoffmann J, Distel L, Herrmann M, Noisternig T, Papadopoulos T, Sauer R, Rödel C: Survivin as a radioresistance factor, and prognostic and therapeutic target for radiotherapy in rectal cancer. Cancer Res 2005, 65:4881-4887.

25. Zhen HN, Li LW, Zhang W, Fei Z, Shi CH, Yang TT, Bai WT, Zhang X: Short hairpin RNA targeting survivin inhibits growth and angiogenesis of glioma U251 cells. Int J Oncol 2007, 31:1111-1117.

26. Congmin G, Mu Z, Yihui M, Hanliang L: Survivin-an attractive target for RNAi in non-Hodgkin's lymphoma, Daudi cell line as a model. Leuk Lymphoma 2006, 47:1941-1948.

27. Jiang $G$, Li J, Zeng Z, Xian L: Lentivirus-mediated gene therapy by suppressing survivin in $B A L B / c$ nude mice bearing oral squamous cell carcinoma. Cancer Biol Ther 2006, 5:435-440.

28. Chen Z, Liang K, Xie M, Wang X, Lü Q, Zhang J: Novel ultrasound-targeted microbubble destruction mediated short hairpin RNA plasmid transfection targeting survivin inhibits gene expression and induces apoptosis of HeLa cells. Mol Biol Rep 2009, 36:2059-2067.

29. Shimamura M, Sato N, Taniyama Y, Yamamoto S, Endoh M, Kurinami H, Aoki M, Ogihara T, Kaneda Y, Morishita R: Development of efficient plasmid DNA transfer into adult rat central nervous system using microbubble-enhanced ultrasound. Gene Ther 2004, 11:1532-1539.

30. Boussif $\mathrm{O}$, Lezoualc'h $F$, Zanta MA, Mergny MD, Scherman D, Demeneix $B$, Behr JP: A versatile vector for gene and oligonucleotide transfer into cells in culture and in vivo: polyethylenimine. Proc Natl Acad Sci USA 1995, 92:7297-7301.

31. Kircheis R, Wightman L, Schreiber A, Robitza B, Rössler V, Kursa M, Wagner E: Polyethylenimine/DNA complexes shielded by transferrin target gene expression to tumors after systemic application. Gene Ther 2001, 8:28-40

32. Das A, Tan WL, Smith DR: Expression of the inhibitor of apoptosis protein survivin in benign meningiomas. Cancer Lett 2003, 193:217-223.

33. Shariat SF, Ashfaq R, Roehrborn CG, Slawin KM, Lotan Y: Expression of survivin and apoptotic biomarkers in benign prostatic hyperplasia. J Urol 2005, 174:2046-2050

34. Hinnis AR, Luckett JC, Walker RA: Survivin is an independent predictor of short-term survival in poor prognostic breast cancer patients. $\mathrm{Br} J$ Cancer 2007, 96:639-645.

35. Ogris $M$, Walker $G$, Blessing $T$, Kircheis $R$, Wolschek M, Wagner E: Tumortargeted gene therapy: strategies for the preparation of ligandpolyethylene glycol-polyethylenimine/DNA complexes. I Control Release 2003, 91:173-181.

36. Hosseinkhani H, Kushibiki T, Matsumoto K, Nakamura T, Tabata Y: Enhanced suppression of tumor growth using a combination of NK4 plasmid DNA-
PEG engrafted cationized dextran complex and ultrasound irradiation. Cancer Gene Ther 2006, 13:479-489.

37. Haag P, Frauscher F, Gradl J, Seitz A, Schäfer G, Lindner JR, Klibanov AL, Bartsch G, Klocker H, Eder IE: Microbubble-enhanced ultrasound to delivery an antisense oligodeoxynucleotide targeting the human androgen receptor into prostate tumours. J Steroid Biochem Mol Biol 2006, 102:103-113.

38. Dittmar KM, Xie J, Hunter F, Trimble C, Bur M, Frenkel V, Li KC: Pulsed highintensity focused ultrasound enhances systemic administration of naked DNA in squamous cell carcinoma model: Initial Experience. Radiology 2005, 235:541-546

39. Howard CM, Forsberg F, Minimo C, Liu JB, Merton DA, Claudio PP: Ultrasound guided site specific gene delivery system using adenoviral vectors and commercial ultrasound contrast agents. I Cell Physiol 2006, 209:413-421.

40. Yanagisawa K, Moriyasu F, Miyahara T, Yuki M, lijima H: Phagocytosis of ultrasound contrast agent microbubbles by Kupffer cells. Ultrasound Med Biol 2007, 33:318-325.

41. Gao Z, Fain HD, Rapoport N: Ultrasound-enhanced tumor targeting of polymeric micellar drug carriers. Mol Pharm 2004, 1:317-330.

42. Bekeredjian R, Kroll RD, Fein E, Tinkov S, Coester C, Winter G, Katus HA, Kulaksiz H: Ultrasound targeted microbubble destruction increases capillary permeability in hepatomas. Ultrasound Med Biol 2007, 33:1592-1598.

43. Lakhani SA, Masud A, Kuida K, Porter GA Jr, Booth CJ, Mehal WZ, Inayat I, Flavell RA: Caspases 3 and 7: key mediators of mitochondrial events of apoptosis. Science 2006, 311:847-851.

44. Chipuk JE, Kuwana T, Bouchier-Hayes L, Droin NM, Newmeyer DD, Schuler M, Green DR: Direct activation of Bax by p53 mediates mitochondrial membrane permeabilization and apoptosis. Science 2004, 303:1010-1014

45. Chen YC, Shen SC, Lee WR, Hsu FL, Lin HY, Ko CH, Tseng SW: Emodin induces apoptosis in human promyeloleukemic $\mathrm{HL}-60$ cells accompanied by activation of caspase- 3 cascade but independent of reactive oxygen species production. Biochem Pharmacol 2002, 64:1713-1724.

\section{doi:10.1186/1756-9966-29-152}

Cite this article as: Chen et al:: Targeted gene delivery in tumor xenografts by the combination of ultrasound-targeted microbubble destruction and polyethylenimine to inhibit survivin gene expression and induce apoptosis. Journal of Experimental \& Clinical Cancer Research 2010 29:152.

\section{Submit your next manuscript to BioMed Central and take full advantage of:}

- Convenient online submission

- Thorough peer review

- No space constraints or color figure charges

- Immediate publication on acceptance

- Inclusion in PubMed, CAS, Scopus and Google Scholar

- Research which is freely available for redistribution
C Biomed Central 